\title{
El Futuro del vehículo ¿eléctrico?
}

\section{The future of ¿electric? vehicle}

\author{
Juan F. Dols Ruis
}

Published online: 12 May 2012

(C) Etrasa 2012

Últimamente es bastante habitual comprobar cómo todos los días son publicadas noticias en los medios de comunicación que nos hablan del futuro del automóvil, y la imperiosa necesidad medio-ambiental de la reducción de emisiones contaminantes provocadas por los gases de efecto invernadero, atribuidas de forma casi inconsciente y en exclusividad a los actuales vehículos de transporte por carretera. Y como si de un mantra se tratara, se "vende" la idea, defendida incluso por la mayoría de las administraciones, de que el futuro del automóvil será a medio plazo totalmente eléctrico. Conviene, sin embargo, tener claro que esta afirmación, desde un punto de vista técnico, está bastante alejada de la realidad. Las últimas novedades presentadas en los congresos internacionales del sector de automoción, como el celebrado el pasado mes de Junio en Valencia y organizado por la European Automotive Engineers Cooperation (EAEC), organización que engloba a las principales asociaciones de ingenieros de automoción que existen en Europa, ponen de manifiesto que el futuro del automóvil a corto y medio plazo pasará por la búsqueda de alternativas al motor de combustión interna puro, tendiendo a la utilización de otros combustibles alternativos como el

J. F. D. Ruis $(\bowtie)$

Ingeniero Industrial, Laboratorio de Automóviles de la UPV, Instituto de Diseño y Fabricación (IDF),

Universidad Politécnica de Valencia,

Valencia, Spain

e-mail: jdols@mcm.upv.es hidrógeno y los biocombustibles, así como a una reducción del peso y potencia del vehículo mediante la búsqueda de nuevos materiales estructurales (es decir, a la construcción de vehículos más pequeños), y el desarrollo de nuevas tecnologías de control inteligente del vehículo.

Según las previsiones del gobierno, y de las políticas energéticas planteadas desde el mismo, se pretende que al finalizar el año 2020, el $10 \%$ de la flota de vehículos sea eléctrica. Sin embargo, y a pesar de todas las campañas publicitarias, planes y subvenciones, la realidad es que en España, según datos de Aniacam, el $0,75 \%$ de los vehículos matriculados hasta Junio de 2011 era de tecnología híbrida, y sólo el $0,03 \%$ de vehículos matriculados eran eléctricos puros. Valores de mercado muy alejados todavía de las expectativas planteadas. Incluso desde los organismos europeos del sector, se tiene como objetivo que para el año 2050 , el $50 \%$ del parque de vehículos sea eléctrico. Este deseo, hoy en día, no deja de ser una utopía debido a las limitaciones técnicas que actualmente presentan estas motorizaciones.

Los avances realizados en el desarrollo de la tecnología de vehículos eléctricos han sido muy importantes en los últimos 20 años (sobre todo en electrónica, control de potencia e informática aplicada a los sistemas de conducción). Pero todavía existen numerosas "barreras tecnológicas" que impiden que a corto y medio plazo se pueda considerar a estas motorizaciones eléctricas como soluciones competitivas 
respecto a las térmicas puras. Estamos hablando, sobre todo, de la necesidad de mejora de la autonomía de las baterías y del aumento de la velocidad de recarga. La autonomía de un vehículo eléctrico puro ronda actualmente, según modelos, entre los 80 a $400 \mathrm{~km}$, con velocidades máximas de 80 a $200 \mathrm{~km} / \mathrm{h}$ y tiempos de recarga de 3,5 a 10 horas, con ciclos de carga de la batería de iónlitio no superiores a 2000 (equivalentes unos 6 años). Incluso hasta que no exista una producción de vehículos eléctricos significativa, el precio de venta resulta una barrera importante, a pesar de las ayudas concedidas por la administración. Los precios habituales de adquisición pueden llegar a ser de hasta el doble que un vehículo térmico de idénticas prestaciones.

Y no deberíamos olvidarnos de la infraestructura, donde se deberán implementar puntos de recarga de vehículos con capacidad técnica suficiente para hacer competitivo su uso. En este sentido, es necesario comentar que para recargar un vehículo durante 8 horas (por ejemplo, en casa), se necesitará una instalación eléctrica que proporcione $220 \mathrm{~V}$ a 15 Amperios y una potencia de 3,3 kW. Si deseáramos recargar un vehículo en 4 horas (en casa o estaciones públicas), la infraestructura requerirá una potencia eléctrica de $6,6 \mathrm{~kW}$ a $220 \mathrm{~V}$ y 30 Amperios. Y en el mejor de los casos, para realizar una recarga en sólo 20-50 minutos (estaciones de servicio o similares), se necesitarán infraestructuras que proporcionen una potencia eléctrica de 50-70 kW a $480 \mathrm{~V}$ y 167 Amperios. Estas limitaciones requerirán un modelo de ciudad distinto, con un planeamiento urbano donde las redes eléctricas puedan suministrar energía eléctrica adicional para los vehículos, y que además estén preparadas, por ejemplo, para optimizar la recarga en horas valle nocturnas.

Pero también desde un punto de vista energético, antes o después deberemos plantearnos la toma en consideración del concepto "well to wheel" (del pozo a la rueda). Es decir, el coste energético y medioambiental de generación de energía eléctrica (que normalmente procede en su mayoría de centrales térmicas que utilizan carbón o derivados del petróleo con una emisión de gases contaminantes y $\mathrm{CO}_{2}$ muy elevada), para llevarla hasta la rueda del vehículo, podría ser incluso mayor que el coste de generar el combustible fósil para ser utilizado en vehículos térmicos. Todo dependerá de la tecnología empleada para la generación de esta energía aguas arriba.

En definitiva, lo que sí podemos afirmar es que sólo a largo plazo se prevé que la tecnología de vehículos eléctricos puros e híbridos, pueda competir con los térmicos puros actuales. De hecho, las previsiones más favorables sí conducen a largo plazo hacia una especialización del mercado, tendiendo a una motorización eléctrica pura para usos exclusivamente urbanos (vehículos de reparto, bicicletas y motocicletas, vehículos de transporte urbano con recorrido predeterminado), mientras que la motorización híbrida (térmica/eléctrica) será utilizada para usos interurbanos (donde el motor térmico será la principal fuente energética en largos recorridos y el motor eléctrico se utilizará en los tramos cortos). Pero para conseguirlo deberemos construir ciudades mejor planificadas, infraestructuras más eficientes energéticamente, y hábitos de consumo más realistas. ¿Estaremos preparados para ello?. 